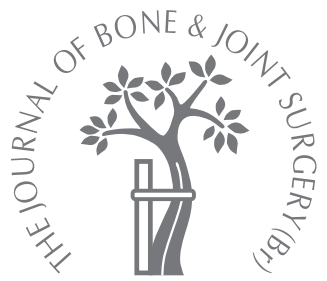

B. Peter,

P.-Y. Zambelli,

J. Guicheux,

D. P. Pioletti

From The Swiss

Federal Institute of

Technology,

Lausanne,

Switzerland

\title{
The effect of bisphosphonates and titanium particles on osteoblasts
}

\author{
AN IN VITRO STUDY
}

B. Peter, PhD, Research Assistant

D. P. Pioletti, PhD, Senior Scientist, Team Leader

Laboratory of Orthopaedic

Research

Swiss Federal Institute of

Technology, Bâtiment AAB,

Station 15, 1015 Lausanne,

Switzerland.

P.-Y. Zambelli, MD, Orthopaedic Surgeon

Hôpital Orthopédique de la

Suisse Romande, Avenue

Pierre Decker 4, 1005

Lausanne, Switzerland.

J. Guicheux, PhD, Senior Scientist, Team Leader

INSERM EMI 9903, School of

Dental Surgery, 1 Place

Alexis Ricordeau, 44042

Nantes Cedex 1, France.

Correspondence should be sent to Dr D. P. Pioletti;

e-mail:

dominique.pioletti@epfl.ch

(C)2005 British Editorial

Society of Bone and

Joint Surgery

doi:10.1302/0301-620X.87B8.

$15446 \$ 2.00$

$J$ Bone Joint Surg [Br]

2005;87-B:1157-63.

Received 1 March 2004;

Accepted after revision

22 November 2004

In an attempt to increase the life of cementless prostheses, an hydroxyapatite-coated implant which releases a bisphosphonate has been suggested as a drug-delivery system. Our in vitro study was designed to determine the maximum dose to which osteoblasts could be safely exposed.

Our findings demonstrated that zoledronate did not impair the proliferation of human osteoblasts when used at concentrations below $1 \mu \mathrm{M}$. Murine cells can be exposed to concentrations as high as $10 \mu \mathrm{M}$.

A concentration of $\mathbf{0 . 0 1 \%}$ of titanium particles did not impair the proliferation of either cell line. Zoledronate affected the alkaline phosphatase activity of murine osteoblasts through a chelation phenomenon. The presence of titanium particles strongly decreased the alkaline phosphatase activity of murine osteoblasts. We did not detect any synergic effect of zoledronate and titanium particles on the behaviour of both human and murine osteoblasts.

The rate of failure of cementless implants can exceed $30 \%$ at 15 years for patients younger than 50 years of age. ${ }^{1}$ The main cause of failure is aseptic loosening after osteolysis caused by stress shielding ${ }^{2}$ or by an inflammatory reaction induced by wear particles or both. ${ }^{3}$ In addition to improvement in the material and wear properties of the implant, new therapy using systemic treatment with bisphosphonates has been considered recently. ${ }^{4}$ However, these drugs have important side-effects including ulcers of the throat or stomach ${ }^{5}$ as well as complicated pathology because of the poor bioavailability of bisphosphonates. ${ }^{6}$ These difficulties could limit the use of bisphosphonate therapy after total hip arthroplasty.

In order to avoid the problems of systemic treatment implants could provide a local drugdelivery system ${ }^{7}$ using a coating with a carrier, such as hydroxyapatite combined with a bisphosphonate. The non-aminobisphosphonates or the aminobisphosphonates could be used ${ }^{8}$ since they have higher efficiency and a higher bioavailability. They do not seem to impede the process of bone-renewal and therefore maintain the strength of the bone whereas the nonaminobisphosphonates are thought to weaken bone over time.

It is important to determine the concentrations of drugs to which osteoblasts can be safely exposed. The drug will be acting at the interface between the bone and the implant where metal debris is generated. These particles will be the principal particle population in the months after implantation. It is therefore important to establish whether the combination of metal particles and bisphosphonates might impair the activity of osteoblasts.

In vitro studies quantifying the simultaneous effect of bisphosphonates and wear particles are scarce. When considering only bisphosphonates, it has been shown that 10 $\mu \mathrm{M}$ pamidronate represents the maximum concentration below which no negative effect is observed either on proliferation or on the activity of alkaline phosphatase (ALP) of human fetal osteoblasts (hFOB). ${ }^{9}$ Alendronate, another bisphosphonate, affected the viability of human osteoblasts at concentrations of 100 $\mu \mathrm{M},{ }^{10}$ but below this no adverse effects were observed. It is of interest that bisphosphonates can induce positive effects on osteoblasts, as was shown with two different bisphosphonates (olpadronate and pamidronate), which increased proliferation in osteoblasts derived from calvaria and $\operatorname{ROS} 17 / 2.8$ up to $0.1 \mu \mathrm{M} .^{11}$

Zoledronate is an aminobisphosphonate which is 1000 times more potent than pamidronate. ${ }^{12}$ Few studies have been performed to evaluate the direct effect of zoledronate on osteoblasts in vitro. ${ }^{13}$ As Klein et $\mathrm{al}^{14}$ have shown, different bisphosphonates induce dif- 
ferent effects on bone. It is difficult to extrapolate the effect of the concentration of one bisphosphonate to another. Zoledronate stimulated proliferation of hFOB by up to $30 \%$ after 72 hours for concentrations ranging from 0.01 $\mathrm{\mu M}$ to $10 \mathrm{\mu M}^{15}$ Longer term studies showed, however, that cell proliferation was finally reduced by $40 \%$ after seven days. The same range of concentration of zoledronate stimulated ALP activity by $30 \%$. By contrast, it has been shown that $10 \mu \mathrm{M}$ zoledronate decreased proliferation of hFOB as compared with a control series. ${ }^{9}$ Viereck et al $^{16}$ demonstrated that the maximum osteoprotegerin (OPG) protein secretion in human primary osteoblasts was obtained with concentrations of zoledronate between $0.001 \mu \mathrm{M}$ and $1 \mu \mathrm{M}$. A concentration of zoledronate of $0.01 \mu \mathrm{M}$ increased ALP activity by a factor of two to four in primary human osteoblasts. These findings show some discrepancy in the action of zoledronate on osteoblasts.

Wear particles have recently been shown to influence the behaviour of osteoblasts in vitro ${ }^{17-20}$ possibly resulting in decreased peri-implant bone formation. Lohmann et $\mathrm{al}^{21}$ showed that particles were found intracellularly, primarily in the cytoplasm and that this led to extensive deformation and damage to organelles. Particles also inhibited the function of osteoblast as shown by a reduction in the development of mineralised nodules and in the area of ALP-positive colonies. $^{22}$

Few studies have evaluated the simultaneous effect of bisphosphonates and particles. One showed that by mixing a bisphosphonate with bone cement, it was possible to inhibit resorption caused by polymethylmethacrylate particles. ${ }^{23}$ Hyvonen and Kowolik ${ }^{24}$ developed a system of bisphosphonate delivery by combining hydroxyapatite particles and clodronate. The phagocytic activity of macrophages was reduced by the presence of clodronate after only 48 hours. These results support the concept of developing an orthopaedic implant which acts as a delivery system for bisphosphonates.

Our aim was to determine in vitro the local concentrations of zoledronate which could be used without a negative effect on the proliferation of osteoblasts and ALP activity and also to verify that there was no synergic negative effect when culturing these cells simultaneously with bisphosphonate and particles.

\section{Materials and Methods}

Cell lines. In order to evaluate in an in vitro model the local effect of different zoledronate concentrations of murine MC3T3-E1 cells ${ }^{25}$ and human MG-63 cells ${ }^{18}$ was used.

Cell culture. The culture medium for MG-63 cells was composed of Dulbecco's minimum essential medium (DMEM) (Sigma-Aldrich, St Louis, Missouri), 10\% fetal bovine serum (Sigma-Aldrich), 1\% antibiotic (penicillin, streptomycin) and fungicide (amphotericin B) (Invitrogen, Carlsbad, California). That for MC3T3-E1 cells consisted of $\alpha$ MEM (BioConcept, Allschwill, Switzerland), $2.2 \mathrm{~g} / \mathrm{l}$ of $\mathrm{NaHCO}_{3}$ (Sigma-Aldrich), $0.5 \%$ essential amino acids
(BioConcept), 10\% fetal bovine serum (Sigma-Aldrich), 1\% L-glutamine (BioWittaker, Rutherford, New Jersey), 50 $\mu \mathrm{g} / \mathrm{ml}$ of L-ascorbic acid (Sigma-Aldrich) and $10 \mathrm{mM} \beta$ glycerophosphate (Sigma-Aldrich). ${ }^{26}$ Ethylenediaminetetra acetic acid (EDTA) (Sigma-Aldrich) at a concentration of $0.01 \mu \mathrm{M}$ was used to control the effect of chelation on the cells since the decrease in $\mathrm{Ca}_{+2}$ ions has an influence on ALP activity. $^{27}$ Zoledronate (1-hydroxy-2-(1H-imidazole-1-yl) ethylidene) 1-bisphosphonic acid disodium salt) was supplied by Novartis Pharmaceuticals AG (Basel, Switzerland). It was dissolved in sterile nanopure water and added to the culture at the first medium exchange.

The cells were collected by trypsinisation and were seeded at a density of 5000 cells per well on 96-well plates. They were incubated at $37^{\circ} \mathrm{C}, 5 \% \mathrm{CO}_{2}$ and $100 \%$ humidity. The cell and particle system had been optimised in previous studies. ${ }^{18,28,29}$ After 24 hours, the medium was replaced with $200 \mu \mathrm{l}$ of medium containing zoledronate in concentrations of $0,0.1,1.0,10.0$ and $50.0 \mu \mathrm{M}$. Half of all the wells contained titanium particles. Half of the medium was changed every three days for fresh culture medium not containing any zoledronate or particles. Proliferation, ALP activity and total protein were measured after four hours and on days 2, 7, 14, 21 and 28. Every condition was tested in triplicate and in three temporally separated culture series. Titanium particles. Commercially pure titanium particles were purchased from Johnson \& Matthey Company (Karlsruhe, Germany). The distribution of particle size was performed by laser diffraction using Malvern MasterSizer equipment (Malvern Instruments Ltd, Malvern, UK). The mean particle size was $4.5 \mu \mathrm{M}$ and the surface area was 0.5 $\mathrm{m}^{2} / \mathrm{mg}$. The particles, autoclaved at $135^{\circ} \mathrm{C}$ for 15 minutes, were mixed with the culture medium under sterile conditions. Based on a particle-weight-to-medium-volume ratio, a concentration of $0.01 \%$ titanium particles was prepared. There were approximately 60000 particles in $1 \mathrm{ml}$ of particle suspension of $0.01 \%$. The titanium particle suspensions were sonicated for 30 minutes in sealed sterile containers before being added to the cell culture. The threshold for titanium particles above which proliferation decreased and below which proliferation was the same as the control was $0.01 \%{ }^{18}$ This concentration was used to quantify a hypothetical synergic effect of zoledronate and titanium particles on the behaviour of osteoblasts.

Proliferation. At every time point, the medium was completely removed by careful pipetting and then replaced with $100 \mu \mathrm{l}$ of fresh medium. In parallel, three wells with fresh medium but without cells were prepared and used as blanks. A proliferation array was performed by adding 10 $\mu \mathrm{l}$ of CellTiter 96 Aqueous One (Promega, Madison, Wisconsin) to every well. The resulting solution was then incubated for one hour at $37^{\circ} \mathrm{C}, 5 \% \mathrm{CO}_{2}$ and $100 \%$ humidity. From each well $100 \mu \mathrm{l}$ were then transferred in a new 96well plate and the absorbance measured at $490 \mathrm{~nm}$ in a Victor plate reader (Wallac, Turku, Finland). To calculate the proliferation, the formula given by Promega was used. The 


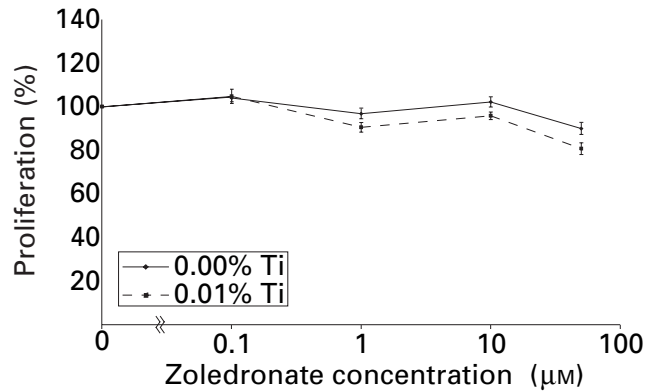

Fig. 1a

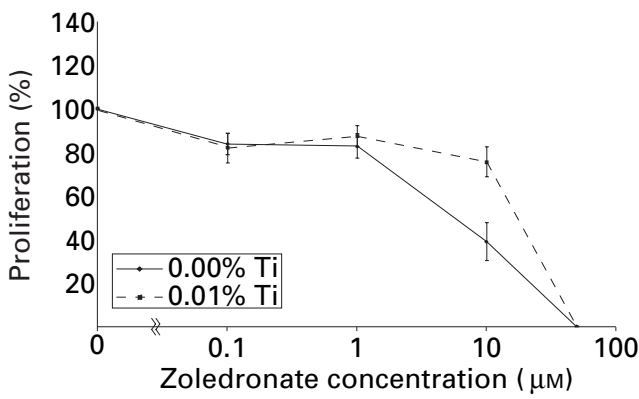

Fig. 1c

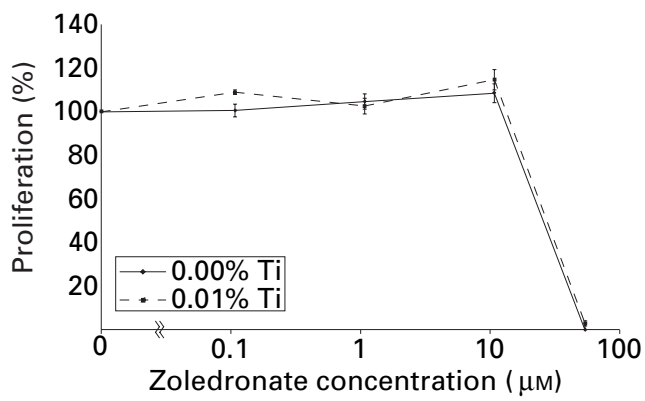

Fig. 1e

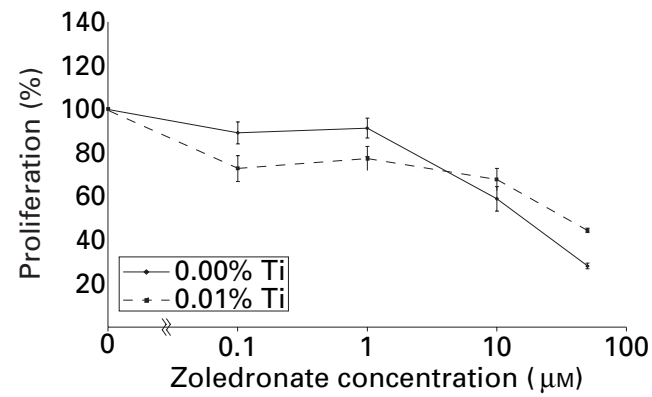

Fig. 1b

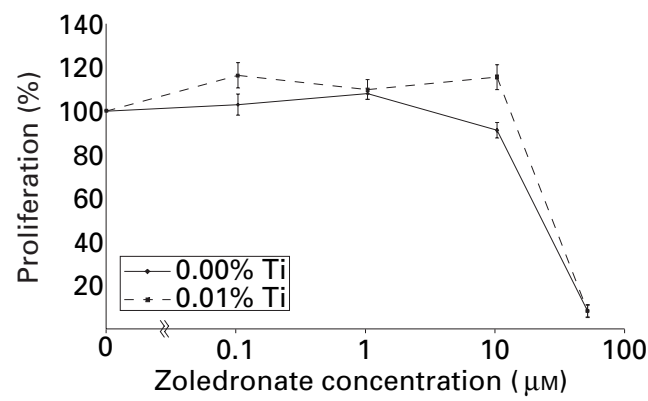

Fig. 1d

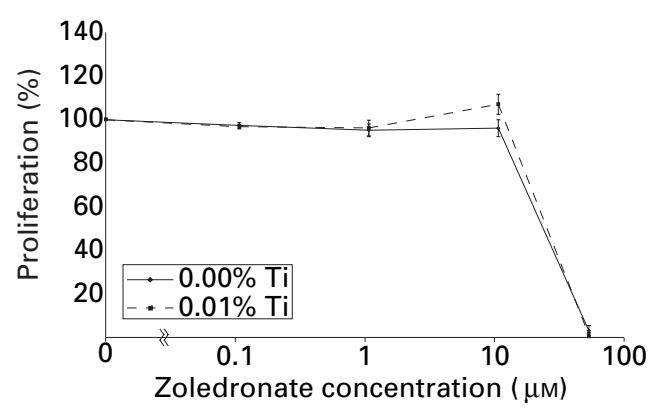

Fig. $1 f$

Mean (SEM) proliferation of MC3T3-E1 cells exposed to concentrations of zoledronate of $0,0.1,1.0,10.0$ and 50.0 $\mu \mathrm{M}$ with and without particles at a) 4 hours, b) day 2, c) day 7, d) day 14 , e) day 21 and f) day 28.

proliferation was normalised by dividing the proliferation of every condition at every time point by the proliferation of the cells not exposed either to zoledronate or to particles at the same time point.

Total protein. At every time point, the medium was completely removed by careful pipetting. All the wells were rinsed twice with phosphate-buffered saline. The plates were stored at $-80^{\circ} \mathrm{C}$ until being processed. To ensure proper cell lysing $100 \mu \mathrm{l}$ of $1 \%$ Triton-X aq were added and pipetted several times. Using the Bio-Rad protein assay (Bio-Rad Laboratories, Hercules, California) and complying with the manufacturer's instructions, the total protein content was measured for every well.
The calibration was made using six dilutions in triplicate of a fetal bovine albumin solution contained in the Bio-Rad Protein Assay II (Bio-Rad Laboratories).

ALP. To determine if differentiation of the cells had taken place, the ALP activity was quantified since it is one of the earliest markers of the differentiation of osteoblasts. ${ }^{30}$ Since MG-63 cells are known to produce very low amounts of ALP, only the ALP activity of MC3T3-E1 cells was measured. The cells were located on the same plates as the cells used for the total protein assay and followed the same treatment; $2 \mu \mathrm{l}$ of lysate were added to $100 \mu \mathrm{l}$ of p-nitrol tablets as substrate (Sigma-Aldrich). The ALP activity was given by the slope of the absorption $v$ s time curve (see Sigma, Pro- 


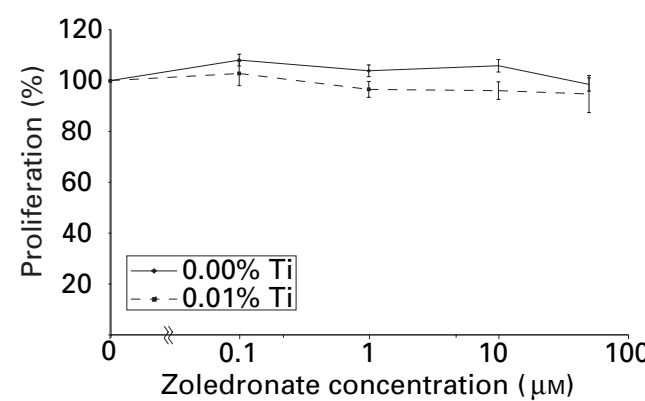

Fig. 2a

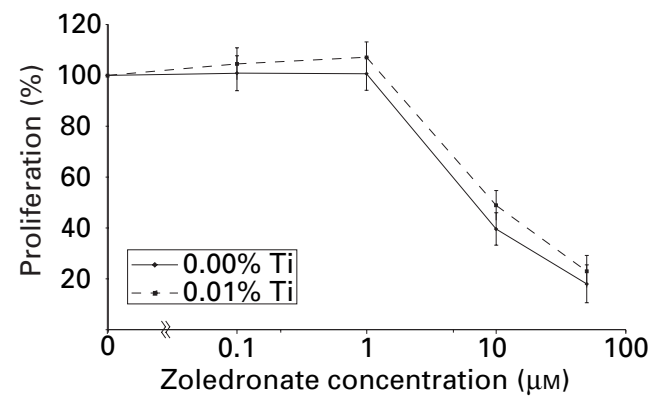

Fig. 2c

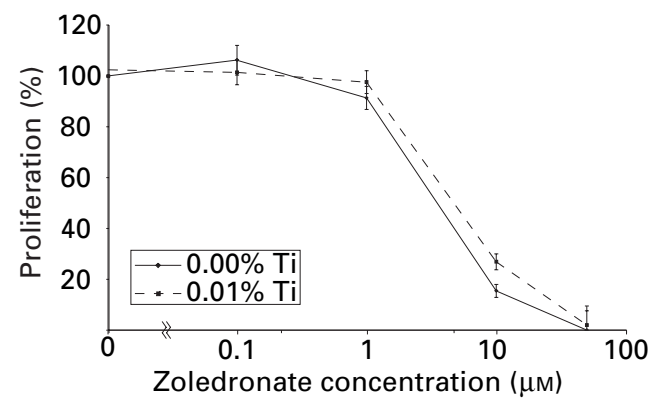

Fig. 2e

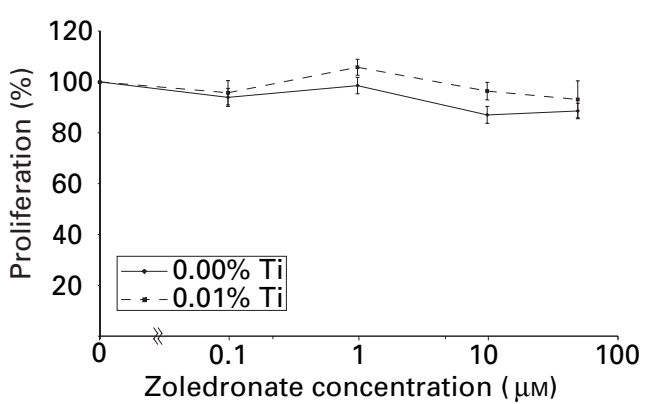

Fig. $2 b$

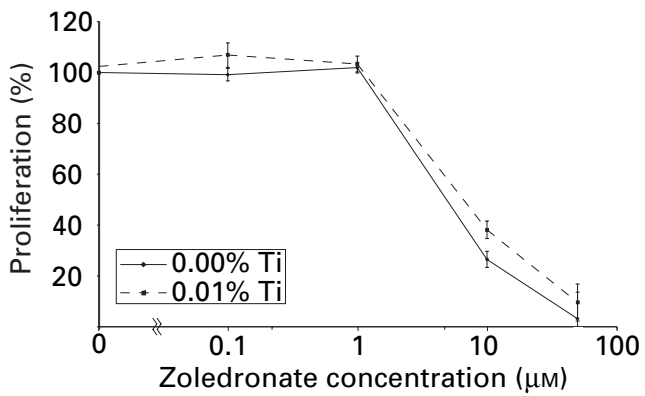

Fig. 2d

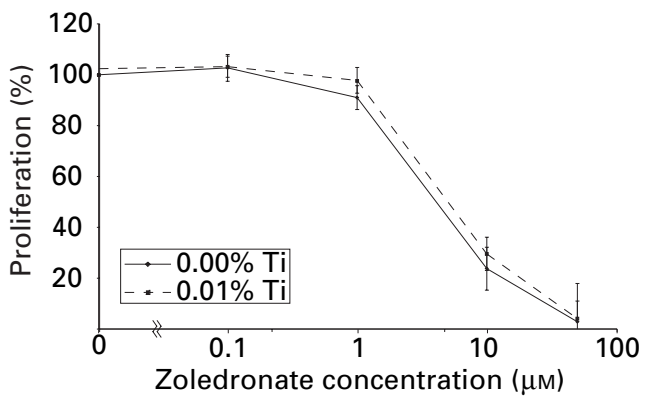

Fig. $2 f$

Mean (SEM) proliferation of MG-63 cells exposed to concentrations of zoledronate of $0,0.1,1.0,10.0$ and $50.0 \mu \mathrm{M}$ with and without particles at a) 4 hours, b) day 2, c) day 7, d) day 14, e) day 21 and f) day 28.

cedure $\mathrm{N} 245$ ) and was normalised for the total protein content which was determined as described above and expressed as $\mathrm{nM}$ p-nitrophenyl phosphate $(\mathrm{PNP}) / \mathrm{min} / \mathrm{mg}$ protein.

Statistical analysis. One-way ANOVA and Student's $t$-test were used to determine the statistical significance of the differences in the results. A probability value of $p<0.05$ was considered to be statistically significant.

\section{Results}

Proliferation. Figure 1 shows the evolution of proliferation of MC3T3-E1 cells exposed to various concentrations of zoledronate and titanium particles. Four hours after seed- ing proliferation was the same for all the different conditions (Fig. 1a). After two days, it slightly decreased for the cells treated with $0.1 \mu \mathrm{M}$ and $1 \mu \mathrm{M}$ zoledronate (Fig. 1b). This finding was independent of the presence of titanium particles. The exposure of the cells to $10 \mu \mathrm{M}$ and $50 \mu \mathrm{M}$ zoledronate significantly decreased the proliferation of cells ( $p<0.001)$. After seven days, concentrations of zoledronate of $0.1 \mu \mathrm{M}$ and $1 \mu \mathrm{M}$ only slightly decreased the proliferation (Fig. 1c). When the MC3T3-E1 cells were exposed simultaneously to $10 \mu \mathrm{M}$ zoledronate and titanium particles, the proliferation became close to the level of that measured on cells treated with the lower doses. When $10 \mu \mathrm{M}$ zoledronate alone was present, proliferation decreased, but was statisti- 


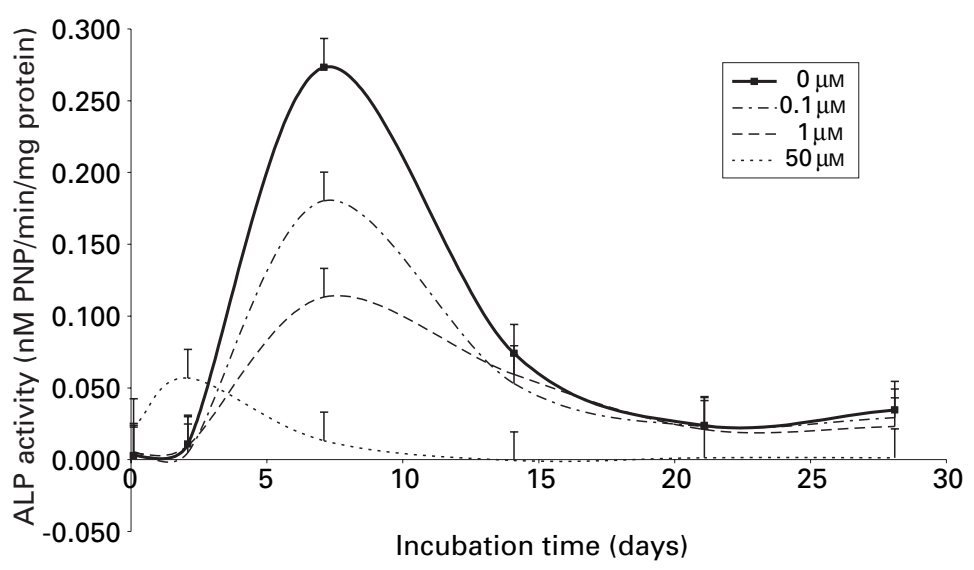

Fig. 3a

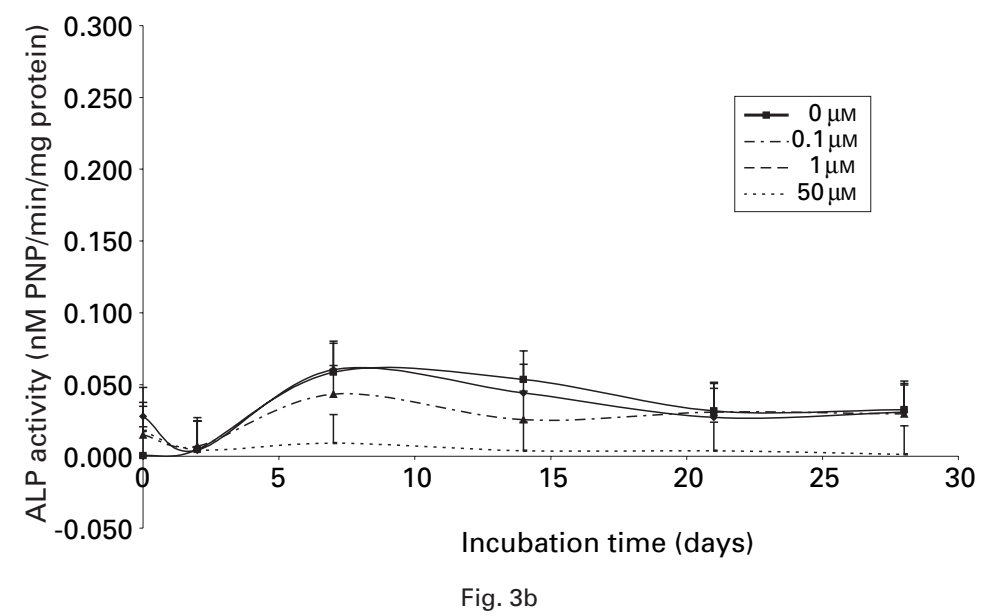

Mean (SEM) ALP activity of MC3T3-E1 cells and at concentrations of zoledronate of 0 , $0.1,1.0,10.0$ and $50.0 \mu \mathrm{M}$ a) without and b) with titanium particles.

cally not significant. At a concentration of $50 \mu \mathrm{M}$ it stopped completely and was inhibited for all subsequent time points. After 14 days, all the zoledronate-treated cells, apart from those treated with $50 \mu \mathrm{M}$, were at the same level as the control cells. This profile remained the same after exposure to zoledronate for 21 and 28 days (Figs $1 \mathrm{~d}$ to $1 \mathrm{f}$ ).

Figure 2 shows the evolution of the proliferation for MG-63 cells exposed to various concentrations of zoledronate and titanium particles. During the first 48 hours, no difference in proliferation was seen as a function of treatment with zoledronate or the presence of titanium particles (Figs $2 \mathrm{a}$ and 2b). At 7 and 14 days, the concentrations of $0.1 \mu \mathrm{M}$ and $1 \mu \mathrm{M}$ of zoledronate gave the same proliferation as the control (Figs $2 \mathrm{c}$ and $2 \mathrm{~d}$ ). At concentrations of $10 \mu \mathrm{M}$ and $50 \mu \mathrm{M}$, proliferation is strongly decreased in a dose-dependent manner $(\mathrm{p}<0.0001)$. This profile was repeated at incubation for 21 and 28 days (Figs $2 \mathrm{e}$ and $2 \mathrm{f}$ ).

EDTA did not show any influence on proliferation for both cell lines (data not shown). No synergic effect of zoledronate and particles was detected on the proliferation of osteoblasts $(\mathrm{p}<0.08)$.

Light microscopy showed that at higher concentrations of zoledronate the osteoblasts were rounded but still attached. At lower concentrations, they did not show any morphological differences as compared with the control group.

ALP. Figure 3 shows the evolution of ALP activity for MC3T3-E1 cells exposed to various concentrations of zoledronate and titanium particles. For the sake of clarity, the curves obtained with $10 \mu \mathrm{M}$ and EDTA are not shown because the $10 \mu \mathrm{M}$ curve was very close to the $50 \mu \mathrm{M}$ curve while the EDTA curve was close to the $1 \mu \mathrm{M}$ curve. In the absence of titanium particles, the ALP activity of the cells decreased with increasing concentration of zoledronate $(\mathrm{p}<0.0001)$ (Fig. 3a). Two patterns were observed. First the control cells, those treated with $0.1 \mu \mathrm{M}$ and $1 \mu \mathrm{M}$ zoledronate and those treated with EDTA, showed an increase in ALP activity as compared with that at day 0 . This culminated after seven days before falling until day 28 . 
Secondly, the cells treated with $10 \mu \mathrm{M}$ and $50 \mu \mathrm{M}$ zoledronate showed a small increase after incubation for 48 hours before decreasing to low levels until day 28. In a dose-dependent manner, the maximum ALP activity decreased from 0.274 to $0.114 \mathrm{nM} \mathrm{PNP} / \mathrm{min} / \mathrm{mg}$ protein when the cells were exposed to no zoledronate and $1 \mu \mathrm{M}$ zoledronate, respectively. When MC3T3-E1 cells were exposed to titanium particles, the evolution of ALP activity with time and concentration of zoledronate was very close to that when no particles were present, apart from the maximum values which were two to five times lower than when the particles were absent $(\mathrm{p}<0.0001)$ (Fig. 3b). The largest decrease in maximum ALP activity after adding particles was for the control cells. The maximum ALP activity was $0.060 \mathrm{nM} \mathrm{PNP} / \mathrm{min} / \mathrm{mg}$ protein. No synergic effect of zoledronate and particles on ALP activity was detected $(\mathrm{p}<0.01)$.

\section{Discussion}

Our study was performed to determine in vitro to which concentration of zoledronate osteoblasts could be safely exposed and to quantify the possible synergic effect of wear particles and zoledronate on the proliferation and differentiation of osteoblasts. This information is important in regard to the development of an orthopaedic implant as a drug-delivery system. Peri-implant bone resorption after total hip arthroplasty has been shown to reach $14 \%$ during the first three months after surgery. ${ }^{31}$ The presence of local bisphosphonate is important for avoiding initial bone resorption and instability of the implant. A recent in vivo study has demonstrated the beneficial effect of local treatment on stability. ${ }^{32}$ Even after a short duration in the body, wear particles are created at the implant-bone interface. It is therefore important to verify that there is no negative synergic effect of particles and zoledronate on osteoblasts.

Few studies have been performed to determine in vitro the effect of zoledronate on the behaviour of osteoblasts while virtually no information is available when bisphosphonate and wear particles are present together. The effect of zoledronate on proliferation was dependent on its concentration, with a clear cut-off concentration below which the proliferation was the same as in the control group, whereas above the cut-off concentration it was close to zero.

The proliferation of osteoblasts treated with zoledronate followed the same profile shown using other bisphosphonates. ${ }^{9,16,33}$ This observation was valid for both cell lines which were used, human and murine. However, two differences were observed in the effect of zoledronate on both cell lines. The first was the cut-off concentration which was 10 $\mu \mathrm{M}$ for murine osteoblasts and $1 \mu \mathrm{M}$ for human osteoblasts. This different sensitivity to concentration of the bisphosphonate has already been observed between mouse and man with alendronate. ${ }^{34}$ The cut-off concentration of zoledronate on the proliferation of human osteoblasts was comparable to that obtained in a previous study. ${ }^{9}$ The second difference was the temporal behaviour at $10 \mu \mathrm{M}$. For human osteoblasts, the proliferation decreased after seven days and stayed at a low level. By contrast for murine osteoblasts exposed to $10 \mu \mathrm{M}$ zoledronate it decreased from day two but then recovered starting from day seven to reach the control level at day 14 . One explanation of this recovery effect may be that proliferation is not suppressed in the murine osteoblast but only slowed down. Cell division during the experiment would result in the production of more osteoblasts which would lead to a concentration of zoledronate that could cross the cut-off level.

As has been shown by Farley et al, ${ }^{27}$ the ALP activity of osteoblasts is inversely proportional to the amount of calcium in the medium. Since zoledronate is known for its ability to precipitate divalent metal ions such as calcium, the concentration of calcium in the medium decreases with increasing concentration of zoledronate. This explains the decreasing ALP activity with increasing zoledronate observed in our study. Moreover, this observation was supported by the result that treatment with EDTA, a known chelating agent, induced a decrease in ALP activity. However, in vivo, this decreased calcium concentration in the presence of zoledronate would probably be counterbalanced by calcium homeostasis.

In previous studies, the effect of particles has given widespread results, but in the main it has been shown that the presence of particles stimulated bone resorption ${ }^{3,35,36}$ and inhibited bone formation. ${ }^{17,19,20,37}$ Using the same titanium particle concentration, similar results were obtained with MG-63 cells. ${ }^{18}$

$\mathrm{Im}$ et $\mathrm{al}^{38}$ showed that the proliferation of osteoblasts and ALP activity was increased when the cells were treated with risedronate and etidronate. This difference in this study may be related to the different bisphosphonate used as well as the different concentrations. However, both studies showed that there was a bisphosphonate concentration which did not impair cell activity. The lowered ALP activity as a result of the presence of particles was significantly stronger than the decrease to zoledronate. Lohmann et al ${ }^{21}$ suggested that the presence of particles either induced the osteoblasts to stay in a less differentiated stage or slowed down protein synthesis in general. They showed also that most of the phagocytosed particles were located in the parts of the cells involved in the assembling and packaging of protein and not in the nucleus. This is supported by the fact that we did not find any effects of the particles on the quantities of mRNA isolated from MC3T3-E1 cells (data not shown). Rodrigo et $\mathrm{a}^{139}$ concluded that post-transcriptional events were influenced by the presence of particles.

In our study, the culture of osteoblasts with zoledronate and titanium particles had neither a positive nor a negative synergy on the behaviour of osteoblasts. We showed that the presence of titanium particles decreased ALP activity more than zoledronate at all concentrations of zoledronate. In the case of a zoledronate-loaded coating or with systemic zoledronate treatment after total hip arthroplasty, the pres- 
ence of zoledronate at a concentration lower than $1 \mu \mathrm{M}$ would not decrease the proliferation or affect the differentiation of osteoblasts.

We conclude that zoledronate decreased proliferation at concentration above $10 \mu \mathrm{M}$ for MC3T3-E1 cells and above $1 \mu \mathrm{M}$ for MG-63 cells. The presence of titanium particles almost completely suppressed ALP activity, while zoledronate influenced the ALP activity in the absence of particles, probably through the chelation of calcium. Importantly, no synergic effect of zoledronate and titanium particles was observed on osteoblasts.

We wish to thank Arlette Kottelat (Laboratory for Orthopaedic Research) for valuable laboratory work and Dr. J. R. Green (Novartis Pharma Research, Basel) for the generous gift of zoledronate.

No benefits in any form have been received or will be received from a commercial party related directly or indirectly to the subject of this article.

\section{References}

1. Herberts P, Malchau H, Garellick G. The Swedish National Hip Arthroplasty Reg ister, annual report 2002. Göteborg: Swedish Orthopaedic Association 2003.

2. Huiskes R. Finite element analysis of acetabular reconstruction: noncemented threaded cups. Acta Orthop Scand 1987;58:620-5.

3. Goodman SB, Huie P, Song Y, et al. Loosening and osteolysis of cemented joint arthroplasties: a biologic spectrum. Clin Orthop 1997;337:149-63.

4. Shanbhag AS, Hasselman CT, Rubash HE. Inhibition of wear debris mediated osteolysis in a canine total hip arthroplasty model. Clin Orthop 1997;344:33-43.

5. Elliott SN, McKnight W, Davies NM, MacNaughton WK, Wallace JL. Alendronate induces gastric injury and delays ulcer healing in rodents. Life Sci 1998;62 77-91.

6. Ezra A, Golomb G. Administration routes and delivery systems of bisphosphonates for the treatment of bone resorption. Adv Drug Delivery Rev 2000;42:175-95.

7. Peter B, Pioletti DP, Terrier A, Rakotomanana LR. Orthopedic implant as drug delivery system: a numerical approach. Comp Meth Biomech Biomed Eng 2001;4 505-13.

8. Fleisch H. Bisphosphonates in bone disease: from the laboratory to the patient. Vol 1, Second ed. London: Parthenon Publishing Group, 1995:176.

9. Reinholz GG, Getz B, Pederson L, et al. Bisphosphonates directly regulate cell proliferation, differentiation, and gene expression in human osteoblasts. Cancer Res 2000;60:6001-7.

10. Garcia-Moreno C, Serrano S, Nacher M, et al. Effect of alendronate on cultured normal human osteoblasts. Bone 1998;22:233-9.

11. Mathov I, Plotkin LI, Sgarlata CL, Leoni J, Bellido T. Extracellular signal-regulated kinases and calcium channels are involved in the proliferative effect of bisphosphonates on osteoblastic cells in vitro. J Bone Miner Res 2001;16:2050-6.

12. Green JR, Muller K, Jaeggi KA. Preclinical pharmacology of CGP $42^{\prime} 446$, a new, potent, heterocyclic bisphosphonate compound. J Bone Miner Res 1994;9:745-51.

13. Pan B, Farrugia AN, To LB, et al. The nitrogen-containing bisphosphonate, zoledronic acid, influences RANKL expression in human osteoblast-like cells by activating TBF-alpha converting enzyme (TACE). J Bone Miner Res 2004;19:147-54

14. Klein BY, Ben-Bassat H, Breuer E, Solomon V, Golomb G. Structurally different bisphosphonates exert opposing effects on alkaline phosphatase and mineralization in marrow osteoprogenitors. J Cell Biochem 1998;68:186-94.

15. Fromigue 0, Body JJ. Bisphosphonates influence the proliferation and the maturation of normal human osteoblasts. J Endocrinol Invest 2002;25:539-46.

16. Viereck V, Emons G, Lauck V, et al. Bisphosphonates pamidronate and zoledronic acid stimulate osteoprotegerin production by primary human osteoblasts. Biochem Biophys Res Commun 2002;291:680-6.

17. Yao J, Cs-Szabo G, Jacobs JJ, Kuettner KE, Glant TT. Suppression of osteoblast function by titanium particles. J Bone Joint Surg [Am] 1997;79:107-12.
18. Pioletti DP, Takei H, Kwon SY, Wood D, Sung KL. The cytotoxic effect of titanium particles phagocytosed by osteoblasts. J Biomed Mater Res 1999;46:399-407.

19. Vermes C, Glant TT, Hallab NJ, et al. The potential role of the osteoblast in the development of periprosthetic osteolysis: review of in vitro osteoblast responses to wear debris, corrosion products, and cytokines and growth factors. J Arthroplasty 2001;16(Suppl 1):95-100.

20. Zreiqat H, Crotti TN, Howlett CR, et al. Prosthetic particles modify the expression of bone-related proteins by human osteoblastic cells in vitro. Biomaterials 2003;24: $337-46$

21. Lohmann $\mathbf{C H}$, Bonewald LF, Sisk MA, et al. Maturation state determines the response of osteogenic cells to surface roughness and 1,25-dihydroxyvitamin D3. J Bone Miner Res 2000;15:1169-80.

22. Anderson GI, Mac0uarrie R, Osinga C, et al. Inhibition of leukotriene function can modulate particulate-induced changes in bone cell differentiation and activity J Biomed Mater Res 2001:58:406-14

23. Sabokbar A, Fujikawa Y, Murray DW, Athanasou NA. Bisphosphonates in bone cement inhibit PMMA particle induced bone resorption. Ann Rheum Dis 1998;57: 614-18

24. Hyvonen PM, Kowolik MJ. Influence of dichloromethylene bisphosphonate on the in vitro phagocytosis of hydroxyapatite particles by rate peritoneal exudate cells: an electron microscopic and chemiluminescence study. Ann Rheum Dis 1992;51:203-9.

25. Guicheux J, Lemonnier J, Ghayor C, et al. Activation of p38 mitogen-activated protein kinase and c-Jun-NH2-terminal kinase by BMP-2 and their implication in the stimulation of osteoblastic cell differentiation. J Bone Miner Res 2003;18:2060-8.

26. Quarles LD, Yohay DA, Lever LW, Caton R, Wenstrup RJ. Distinct proliferative and differentiated stages of murine MC3T3-E1 cells in culture: an in vitro model of osteoblast development. J Bone Miner Res 1992;7:683-92.

27. Farley JR, Hall SL, Tanner MA, Wergedal JE. Specific activity of skeletal alkaline phosphatase in human osteoblast-like cells regulated by phosphate, phosphate esters, and phosphate analogs and release of alkaline phosphatases activity inversely regulated by calcium. J Bone Miner Res 1994;9:497-508.

28. Pioletti DP, Leoni I, Genini D, et al. Gene expression analysis of osteoblastic cells contacted by orthopaedic implant particles. J Biomed Mater Res 2002;61:408-20.

29. Pioletti DP, Kottelat $\mathbf{A}$. The influence of wear particles in the expression of osteoclastogenesis factors by osteoblasts. Biomaterials 2004;25:5803-8.

30. Hakeda Y, Ikeda E, Kurihara N, et al. Induction of osteoblastic cell differentiation by forskolin: stimulation of cyclic AMP production and alkaline phosphatase activity. Biochim Biophys Acta 1985;838:49-53.

31. Venesmaa PK, Kroger, HP, Miettinen HJ, et al. Induction of osteoblastic cell differentiation by forskolin: stimulation of cyclic AMP production and alkaline phosphatase activity. Biochim Biophys Acta 1985;838:49-53.

32. Peter B, Pioletti DP, Laib S, et al. Calcium phosphate drug delivery system: influence of local zoledronate release on bone implant osteointergration. Bone 2005;36: 52-60.

33. Giuliani N, Pedrazzoni M, Negri G, et al. Bisphosphonates stimulate formation of osteoblast precursors and mineralized nodules in murine and human bone marrow cultures in vitro and promote early osteoblastogenesis in young and aged mice in vivo. Bone 1998;22:455-61

34. Yamaguchi K, Motegi K, Iwakura Y, Endo Y. Involvement of interleukin-1 in the inflammatory actions of aminobisphosphonates in mice. Br J Pharmacol 2000;130: 1646-54.

35. Takei H, Pioletti DP, Kwon SY, Sung KL. Combined effect of titanium particles and TNF-alpha on the production of IL-6 by osteoblast-like cells. J Biomed Mater Res 2000;52:382-7.

36. Shanbhag AS, Macaulay W, Stefanovic-Racic M, Rubash HE. Nitric oxide release by macrophages in response to particulate wear debris. J Biomed Mater Res 1998;41:497-503

37. Pioletti DP, Rakotomanana LR. Can the increase of bone mineral density following bisphosphonates treatments be explained by biomechanical considerations? Clin Biomech 2004;19:170-4

38. Im GI, Qureshi SA, Kenney J, Rubash HE, Shanbhag AS. Osteoblast proliferation and maturation by bisphosphonates. Biomaterials 2004;25:4105-15.

39. Rodrigo AM, Martinez ME, Escudero ML, et al. Influence of particle size in the effect of polyethylene on human osteoblastic cells. Biomaterials 2001:22:755-62. 